\title{
Preparation, Properties and Microstructure of SiC Particle Reinforced Al-Si Matrix Composite
}

\author{
Shiming $\mathrm{Hao}^{1,3}$, Jingpei Xie ${ }^{2, *}$, Aiqin Wang ${ }^{2}$ and Ming Fang ${ }^{2}$ \\ ${ }^{1}$ School of Physics and Engineering, Henan University of Science and Technology, Luoyang 471003, China \\ ${ }^{2}$ College of Materials Science and Engineering, Henan University of Science and Technology, Luoyang 471003, China \\ ${ }^{3}$ Physical Engineering College and Laboratory of Materials Physics of the Ministry of Education of China, \\ Zhengzhou University, Zhengzhou 450052, China
}

\begin{abstract}
The $\mathrm{SiC}$ particles reinforced Al-30Si matrix composite was fabricated by vacuum hot pressing techniques. Mechanical properties of the composite were measured, and the microstructure was observed using SEM, XRD, and TEM. The results show that SiC particles and Si particles were dispersed uniformly in the matrix, the interfaces of the $\mathrm{SiC} / \mathrm{Si}, \mathrm{SiC} / \mathrm{Al}$, and the $\mathrm{Si} / \mathrm{Al}$ are good and did not find the formation of $\mathrm{Al}_{4} \mathrm{C}_{3}$; composites have a low coefficient of thermal expansion $\left(10.4 \times 10^{-6} \mathrm{~K}^{-1}\right)$ and decent tensile strength $(192 \mathrm{MPa})$. The analysis of the fractograph reveals the fracture mechanism of $\mathrm{SiC}$ particle reinforced $\mathrm{Al}-\mathrm{Si}$ matrix composite. The fracture of composite is primarily dominated by the fracture of brittle $\mathrm{Si} / \mathrm{SiC}$ particles and the subsequent link up of damage through the matrix. [doi:10.2320/matertrans.M2013473]
\end{abstract}

(Received December 27, 2013; Accepted February 13, 2014; Published April 4, 2014)

Keywords: aluminum-silicon matrix composite, microstructure, tensile strength, thermal expansion coefficient, vacuum hot pressing

\section{Introduction}

SiC particles (SiCp) reinforced aluminum matrix composites exhibit unusual combinations of mechanical, physical and thermal properties, high stiffness and strength, high elastic modulus, good wear resistance, and good dimensional stability while retaining relatively low density, are attractive for many structural applications, especially in the aerospace and automobile industries. ${ }^{1,2)}$ Some packaging materials are also used in the aerospace, for which not only suitable coefficients of thermal expansion and thermal conductivity are required but also low density and appropriate mechanical strength.

At present the basic mechanical properties of composite materials, mostly concentrated in the low volume fraction $\mathrm{SiCp} / \mathrm{Al}$ composites. ${ }^{3,4)}$ High volume fraction in Sip/Al composites have lower coefficient of expansion and better machinability. However, the strength of the $\mathrm{Al} / \mathrm{Si}$ composites is lower. The addition of $\mathrm{SiC}$ particle was expected to enhance the thermal conductivity and tensile strength. 5,6 ) Chien et al. ${ }^{7,8)}$ found that the fracture path of $\mathrm{Al} / \mathrm{Sip}$ composites includes cracks not only through silicon particles but also along the matrix/particle interface. Prepared using the solid-liquid method at high temperatures $\mathrm{SiCp} / \mathrm{Al}$ composite generate easily brittle phase $\mathrm{A}_{4} \mathrm{C}_{3}$ at the interface and affect the mechanical properties. Preparation using powder process metallurgy can effectively avoid the unfavorable interfacial chemical reaction at low temperatures, the product quality easy to control and the volume fraction of particles in the composite. But the inhomogeneous distribution or aggregation of the reinforced particles in the matrix are the biggest problems.

It is difficult to ensure the higher tensile properties because of brittle phase volume fraction is greater than the volume fraction of the plastic phase. The particle distribution of enhanced particle and interfacial bonding of the particles/ matrix directly affects the tensile strength of the material. In

*Corresponding author, E-mail: xiejp@ haust.edu.cn this study, the Al-Si alloy as the matrix (silicon content in the alloy is $30 \%$ ), fabricated by hot pressing of $\mathrm{SiC}$ particles reinforced Al-30Si matrix composites, hope to explore a low thermal expansion and good mechanical properties composites. The microstructure, interface structure and its fracture mechanism are investigated.

\section{Materials and Experimental Procedures}

Experiment raw material is Al-30Si powdered alloy which was made through ultrasonic spray deposited method, the original particle size is 500 meshes. The reinforcement is $\mathrm{SiC}$ powder, the original particle sizes are 325 meshes. In this composite material, the volume fraction of $\mathrm{SiC}$ particle was $25 \%$. The volume percentage of the Al-30Si alloy powder and $\mathrm{SiC}$ particles is $3: 1$ in the composite, milling mixture time is $2.5 \mathrm{~h}$, and milling speed is $260 \mathrm{r} / \mathrm{min}$.

In the experiment composite material was prepared in vacuum hot pressing method in VDBF-250 vacuum diffusion welding test machine. The pressing temperature is $853 \mathrm{~K}$ and the holding time is $3 \mathrm{~h}$. The original billet was cylindrical with an initial diameter of approximately $30 \mathrm{~mm}$ and a height of $60 \mathrm{~mm}$. A variety of test specimens have been made by machining. Tensile test at ambient room temperature was carried out for the sheets at a nominal strain rate of $6.7 \times 10^{-2} \mathrm{~s}^{-1}$ by using an Shimadzu AG-I $250 \mathrm{KN}$ precision universal testing machine. The specimen for tensile test was $27 \mathrm{~mm}$ in gage length and $5 \mathrm{~mm}$ in gage width. The coefficient of thermal expansion (CTE) was measured using PYC-III Thermal Expansion Coefficient Tester equipment with $0.1 \mu \mathrm{m}$ and $0.1 \mathrm{mN}$ load displacement resolution. CTE was measured during a programmed heating rate of $10 \mathrm{~K} / \mathrm{min}$ from room temperature $293 \pm 1$ to $433 \pm 1 \mathrm{~K}$. Phase composition of the composites analysis by the $\mathrm{D} / \mathrm{rmx}-2400 \mathrm{X}$-ray diffraction analyzer. The microstructural observations were performed using a JSM$5600 \mathrm{LV}$ scanning electron microscope (SEM) and a JEM 2100 transmission electron microscope (TEM) operated at $200 \mathrm{kV}$. 

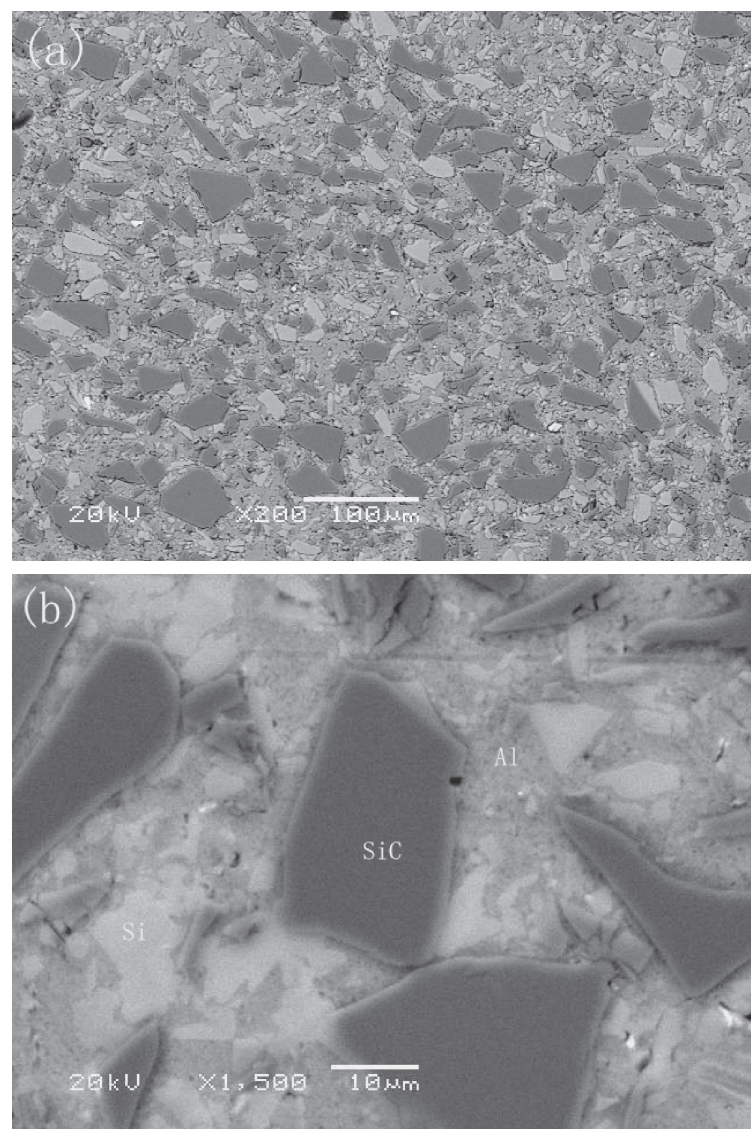

Fig. 1 SEM photographs of composites (a) low multiples (b) high multiples.

\section{Results and Discussion}

\subsection{Microstructure}

$\mathrm{SiC}$ distributions in the materials are essential and affect directly the performance of the composites. If the $\mathrm{SiC}$ segregation occurs between the particles due to contact with each other, will inevitably result in the hole in the material. The microstructure of the $\mathrm{SiCp} / \mathrm{Al}-\mathrm{Si}$ composite is shown in Fig. 1. It was found that $\mathrm{SiC}$ particles and $\mathrm{Si}$ particles were distributed uniformly in the matrix, without any particle clustering. As a result of the high pressure during the solidification process, a dense microstructure was obtained. This was helpful for the improvement of heat conduction. However, a small number of the $\mathrm{SiC}$ and precipitated $\mathrm{Si}$ particles appeared crack flaw, in the angle place. Figure 2 shows the XRD pattern of composite materials. It can be seen that the phase product are $\mathrm{Al}, \mathrm{Si}$ and $\mathrm{SiC}$ phase. The hot pressing sintering did not produce other phases; there are no interface product $\mathrm{Al}_{4} \mathrm{C}_{3}$ and other chemical reaction.

\subsection{Tensile strength and the coefficient of thermal expansion}

The lower CTEs could avoid thermal mismatch with those ceramic substrates or semiconductor materials in electronic packaging applications. Low thermal expansion properties of the composites are achieved by adjusting the volume fraction of $\mathrm{SiC}$ and $\mathrm{Si}$ particles. For this $\mathrm{SiC}$ particle reinforced $\mathrm{Al}-\mathrm{Si}$ matrix composites, the tensile strength is $192 \mathrm{MPa}$ which is much larger than the tensile strength $(89 \mathrm{MPa})$ of unrein-

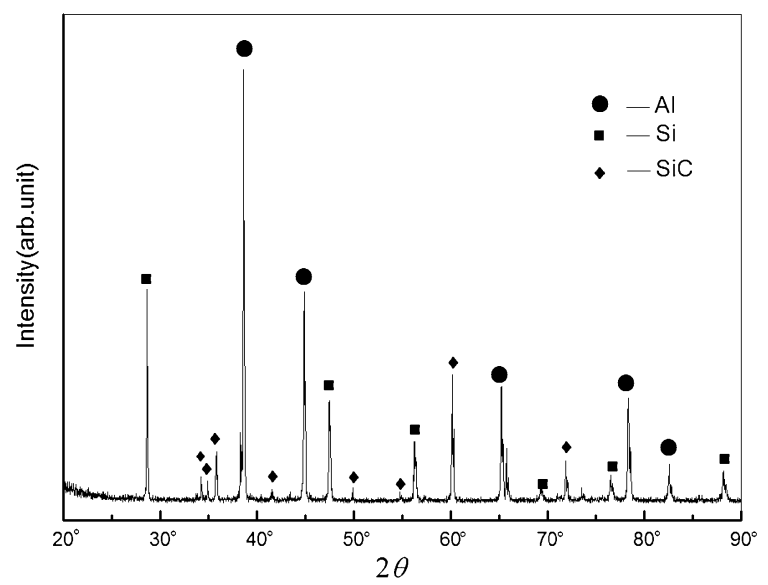

Fig. 2 XRD pattern of composite.
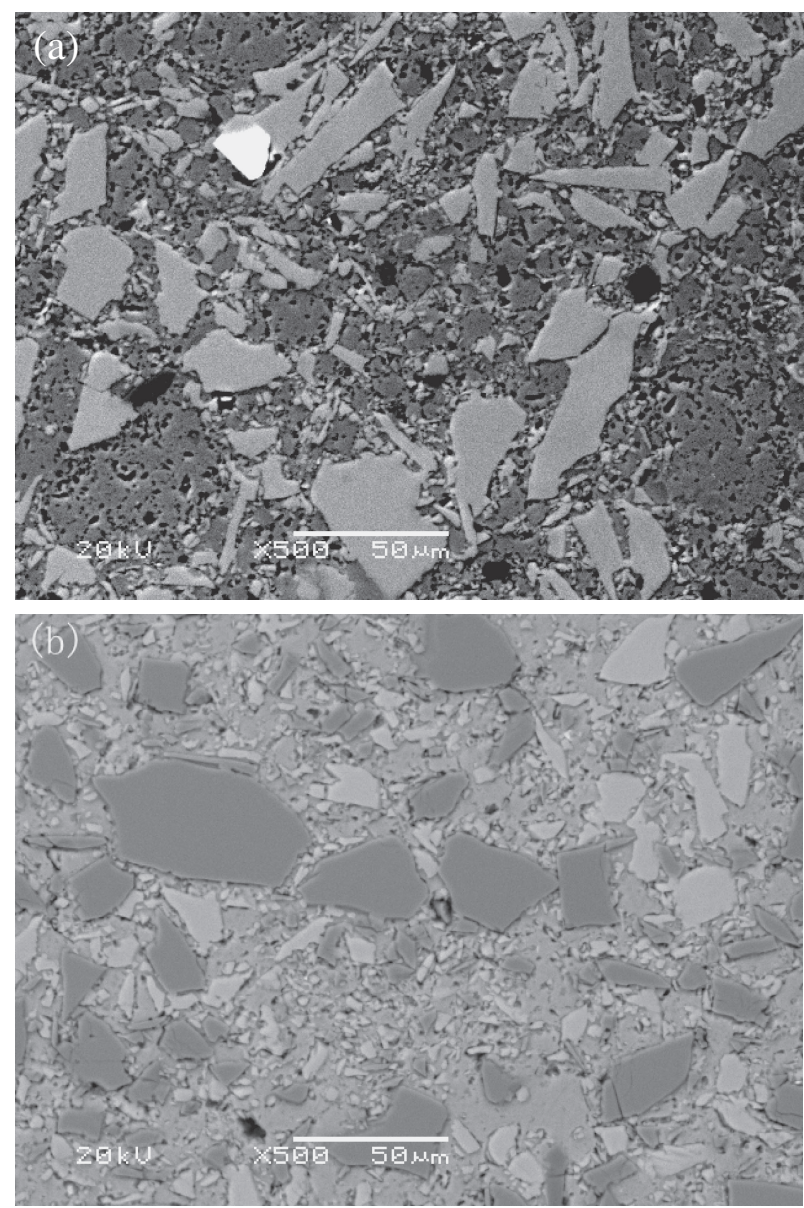

Fig. 3 Microstructures showing size and morphology of silicon particles in (a) Al-30Si alloy, (b) $25 \% \mathrm{SiCp} / \mathrm{Al}-\mathrm{Si}$ matrix composite.

forced Al-30Si alloy. The CTE is $10.4 \times 10^{-6} \mathrm{~K}^{-1}$. Primary silicon in the alloy is hard and brittle in the alloy phase. With the increase of silicon content in the alloy, resulting in the alloy force area is reduced, weakening effect has been strengthened. SiC particle can take up the second phase to strengthen the role of brittle phase.

Figure 3 show the microstructures of silicon particles in unreinforced $\mathrm{Al}-30 \mathrm{Si}$ alloy and Al-30Si alloy reinforced with $25 \% \mathrm{SiC}$ particles, respectively. It can be noted that there is a significant refinement in the size of silicon particles 

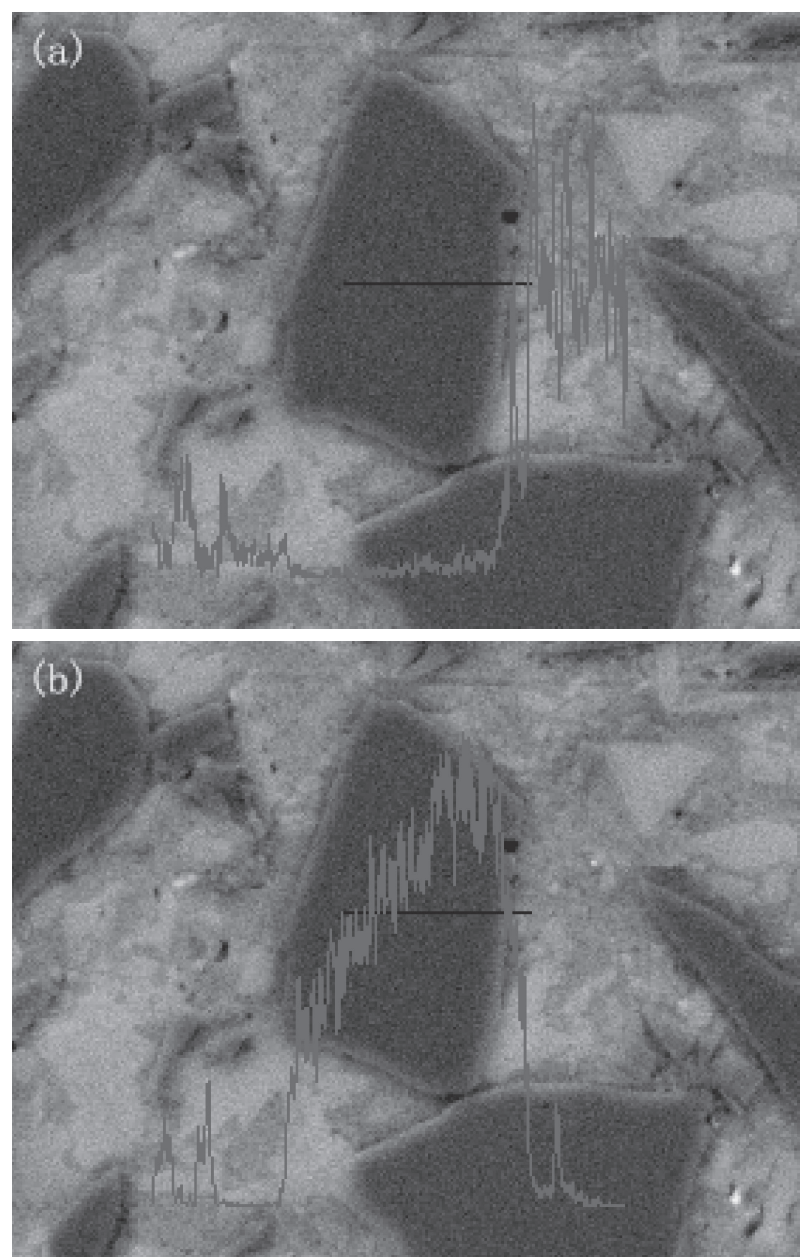

Fig. 4 EDS element line-scanning spectra of the composite interface (a) aluminum element (b) silicon element.

with an addition of SiC particle. Primary Si phase changes from coarse strip to lump or fine strip and the change is not going on completely. It can be observed that very few silicon particles are heterogeneously nucleated on the SiC particle. Small size $\mathrm{Si}$ particles are also considered to reduce the possibility of particle debonding and fracture even under severe stress condition at the particulate-matrix interface.9)

\subsection{Interface analysis}

In order to study the combination of $\mathrm{SiC}$ particles and aluminum, and the transformation in the distribution of the elemental composition at the interface, the interface line scanning of the interface shown in Fig. 4. Aluminum and silicon element distribution curve showed that almost no diffusion between $\mathrm{SiC}$ particles and aluminum matrix. This shows that in the hot pressing process, physical bond is the main combination ways.

In order to reveal the interfacial details of reinforcement and Al matrix, TEM was used to study the interfacial microstructure of the composites. Figure 5 shows the morphologies of the interface between the reinforcements and the Al matrix. Figure 5(a) is a representative interface of the $\mathrm{SiCp} / \mathrm{Al}$, the interface is clean and free from any interfacial reaction products. An interface between $\mathrm{Sip} / \mathrm{Al}$ is shown in Fig. 5(b), the interface is very clean, smooth and straight. The interface between $\mathrm{SiC} / \mathrm{Si}$ is also free from any
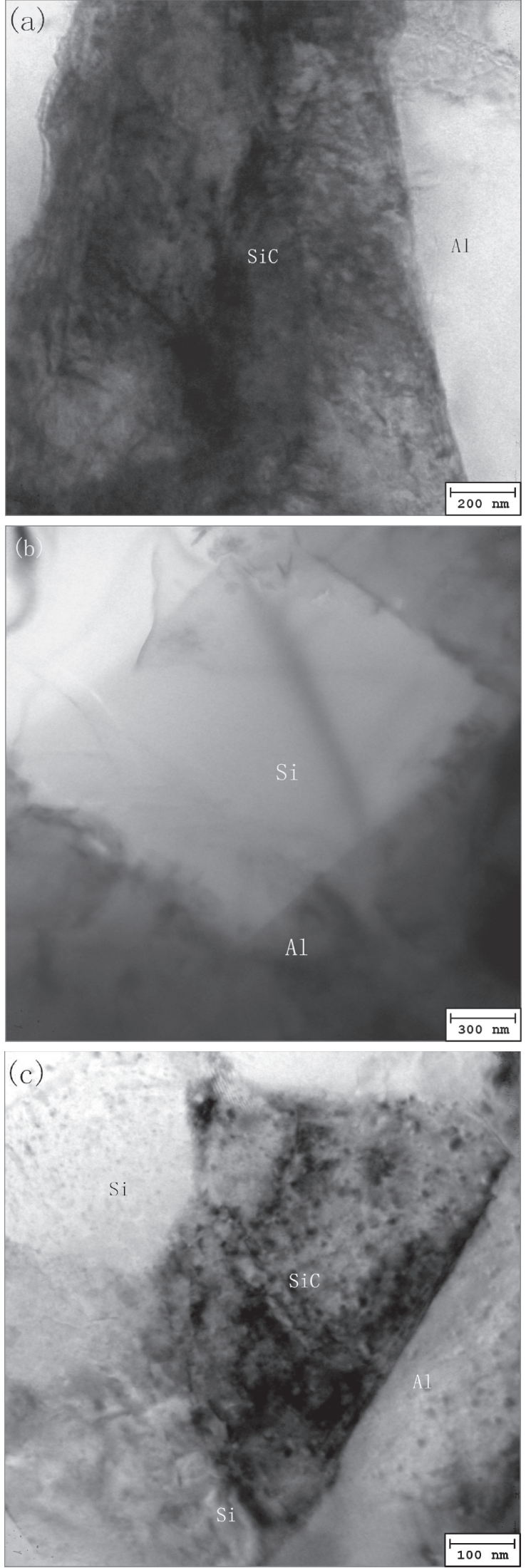

Fig. 5 TEM micrograph showing morphology of composite interface (a) $\mathrm{SiC} / \mathrm{Al}$, (b) $\mathrm{Si} / \mathrm{Al}$, (c) $\mathrm{SiC} / \mathrm{Sip}$.

interfacial reaction products. To sum up, the good interfacial bonding exists between the Al matrix, Si particle and $\mathrm{SiC}$ particle. 


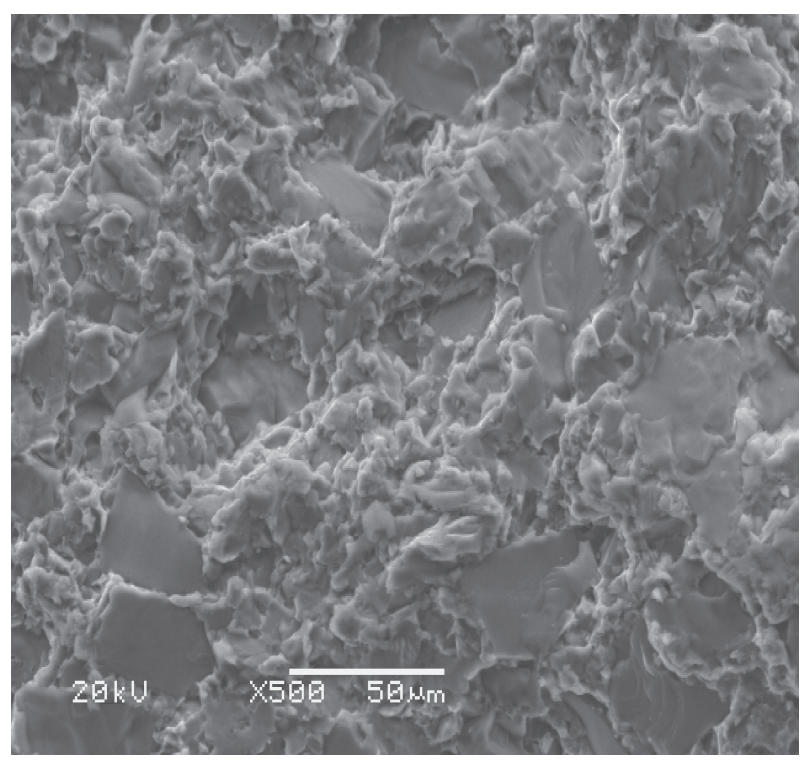

Fig. 6 SEM image showing fracture micrograph of composite.

TEM observations indicated that the Si phase in the matrix rarely nucleated on the surface of SiC particles. Wang et al. ${ }^{10)}$ have reported the primary Si phase nucleation on $\mathrm{SiC}$ particles. Generally speaking, the solid/liquid interface of crystals is an important factor that would influence the heterogeneous nucleation of silicon on $\mathrm{SiC}$ particles. In the present study, this combination is rare because the liquid is few when the composite prepared by Powder Metallurgy route.

\subsection{Fracture analysis}

Figure 6 shows the fracture surface of the composites. Even though the fractographs indicate brittle fracture at macro level, some ductile features in the form of dimples are evident due to the localized deformation at the fracture surface. Two characteristics were observed in the study of fracture surfaces: (1) fracture surfaces have dimple morphology; (2) the sample showed flat facets of the fractured $\mathrm{SiC}$ particle or $\mathrm{Si}$ particle and uniformly distributed dimples around the reinforcement particles. Large silicon particles have a lower fracture stress and are prone to cracking. The failure mode of the composites is predominantly brittle fracture through $\mathrm{SiC}(\mathrm{Si})$ particle.

\section{Conclusions}

In summary, an Al-30Si matrix composite reinforced with 25 vol\% $\mathrm{SiC}$ particles was produced in this work.

(1) The SiC particle reinforced Al-30Si matrix composite was dense and porosity free macroscopically. $\mathrm{SiC}$ particle dispersed uniformly in the matrix.

(2) Compared with the Al-Si alloy, the SiC particle reinforced Al-Si matrix composite have low coefficient of thermal expansion $\left(10.4 \times 10^{-6} \mathrm{~K}^{-1}\right)$, while maintain the high tensile properties (192 MPa).

(3) The fracture surface morphology shows there are dimple morphology and cleavage of particles. The failure mode of the composite is predominantly brittle fracture through $\mathrm{SiC}$ and $\mathrm{Si}$ particle.

(4) The interfaces of the $\mathrm{SiC} / \mathrm{Si}, \mathrm{SiC} / \mathrm{Al}$, and the $\mathrm{Si} / \mathrm{Al}$ are good and are free from any interfacial reaction products. There no diffusion between $\mathrm{SiC}$ particles and Al matrix.

\section{Acknowledgements}

This work was supported by National Natural Science Foundation of China (No. 51371077).

\section{REFERENCES}

1) A. B. Pandey and B. S. Miracle: Metall. Mater. Trans. A 31 (2000) 921-936.

2) B. Miracle: Compos. Sci. and Technol. 65 (2005) 2526-2540.

3) T. J. A. Doel and P. Bowen: Compos. Part A 27 (1996) 655-665.

4) J. M. Torralba, C. E. Da Costa and F. Velasco: J. Mater. Process. Technol. 133 (2003) 203-206.

5) Q. G. Zhang, H. X. Zhang and M. Y. Gu: Mater. Lett. 58 (2004) 35453550 .

6) Q. G. Zhang and M. Y. Gu: Mater. Sci. Eng. A 419 (2006) 86-90.

7) C. W. Chien, S. L. Lee, J. C. Lin and M. T. Jahn: Mater. Lett. 52 (2002) 334-341.

8) C. W. Chien, S. L. Lee and J. C. Lin: Mater. Sci. Technol. 19 (2003) 1231-1234.

9) V. C. Srivastava, R. K. Mandal and S. N. Ojha: Mater. Sci. Eng. A 304306 (2001) 555-558.

10) W. Wang, F. Ajersch and J. P. A. Löfvander: Mater. Sci. Eng. A 187 (1994) 65-75. 